\title{
Antidepressant Prescribing Patterns for Depressive and Anxiety Disorders in a Singapore Hospital
}

\author{
Teck Hwee Soh ${ }^{1}$, Leslie Lim ${ }^{1}$, Herng Nieng Chan ${ }^{1}$, Yiong Huak Chan ${ }^{2}$ \\ ${ }^{1}$ Department of Psychiatry, Singapore General Hospital, Singapore \\ ${ }^{2}$ National University Health System, Singapore \\ Email: "leslie.lim.e.c@sgh.com.sg
}

Received 5 February 2015; accepted 2 March 2015; published 6 March 2015

Copyright (C) 2015 by authors and Scientific Research Publishing Inc.

This work is licensed under the Creative Commons Attribution International License (CC BY). http://creativecommons.org/licenses/by/4.0/

(c) (i) Open Access

\section{Abstract}

Objective: Although antidepressants are the recommended first-line pharmacological treatments for depressive and anxiety disorders, their prescribing patterns have not been studied in Singapore. We investigate antidepressant prescription patterns for outpatients with depressive and anxiety disorders in a general hospital in Singapore. We hypothesize that intolerance to side effects and lack of efficacy may contribute to medication switching, and that initiation of antidepressant therapy is not easily tolerated. Methods: A retrospective review of the casenotes of outpatients was carried out between January 2013 and December 2013. A total of 206 patients were randomly selected. The study was approved by the hospital's institutional review board. Data analysis was carried out using SPSS version 18. Results: There were more females than males (ratio 1.7:1) with a mean age of $50.6 \pm 15.2$ years. Depressive disorder, comprising $50 \%$ of the sample, was the most frequent diagnosis followed by anxiety disorder (27.2\%), mixed anxiety-depression (16\%) and adjustment disorder $(5.8 \%)$. Almost all patients $(97.1 \%)$ were prescribed antidepressants, the most common being selective serotonin reuptake inhibitors (SSRI) $(75.5 \%)$, followed by the noradrenaline and specific serotonin antidepressant (NaSSA) (13.5\%) and tricyclic antidepressants (TCA) $(8.5 \%)$. Patients prescribed SSRIs tended to be younger and better educated $(p=0.0005)$. More than half of the patients $(52.1 \%)$ required antidepressant switching mainly due to lack of efficacy and intolerance of side effects. Combination therapy was prescribed for $17 \%$ of patients with SSRI-NaSSA, the most preferred combination. Nearly a quarter $(23.8 \%)$ patients required augmentation therapy with atypical antipsychotics. Combination $(p=0.024)$ and augmentation $(p$ $=0.033$ ) were utilized more often for depression than for anxiety disorders. Conclusion: Antidepressant medications are commonly prescribed for depression and anxiety disorders. The main reasons for switching antidepressants were intolerance and lack of efficacy. That about half of the patients reported side effects necessitating medication change confirmed our hypothesis that an-

*Corresponding author. 
tidepressant therapy was not easy to initiate. This has important implications for treatment adherence and outcome.

\section{Keywords}

Antidepressants, Anxiety Disorders, Depressive Disorders, Augmentation, Combination, Switching

\section{Introduction}

Antidepressant prescribing patterns have shown an increasing trend over the years [1] [2]. These medications are recommended first-line treatments for depressive and anxiety disorders [1] [3]. According to published evidence, it would appear that selective serotonin reuptake inhibitors have become the most commonly prescribed class of antidepressant drugs worldwide [1]-[5]. The clinician's decision on which antidepressant to prescribe is complex and multifactorial, with the ultimate choice affected by patient factors and psychosocial reasons [6]. Tolerability and efficacy of medications influence patient adherence and this in turn affects treatment outcomes. Should these agents be less than effective in achieving remission? Successful augmentation with lithium [7] buspirone [8], bupropion [9], and atypical antipsychotic agents [10] has been documented. Combination with mirtazapine has been supported on the basis of a randomized placebo control trial [11]. In cases of treatment resistant depression and anxiety disorders, a variety of therapeutic options have been proposed [12]-[14].

However, there is scant data on the usage of antidepressants in South East Asia. A multi-centered international study on antidepressant prescription patterns in East Asia in 2007 showed that selective serotonin reuptake inhibitors (SSRIs) were the most commonly prescribed antidepressants [15]. This finding was corroborated by other authors who also found that SSRIs formed the majority of prescriptions [16].

This study seeks to investigate the prescribing patterns of antidepressants for psychiatric outpatients with depressive and anxiety disorders in a general hospital psychiatric department in Singapore, with particular reference to switching, combination and augmentation therapy.

We hypothesize that side effect intolerance and lack of efficacy may contribute to switching before arriving at the final choice of antidepressant. Antidepressant class, whether singly or combined, details of augmentation strategy, and reasons for switching facilitate understanding as to why patients/ doctors prefer/reject one antidepressant over another. Such information is invaluable for the guidance of trainee psychiatrists in this country.

\section{Methods}

The study is a retrospective case record review of outpatients attending psychiatric clinics at the Department of Psychiatry in the Singapore General Hospital. This is the largest general hospital in the country and also serves as a teaching hospital for undergraduates and postgraduate students and residents.

The study sample included patients attending outpatient follow up between January 2013 and December 2013. A random sampling of one in 5 case records of patients was performed.

Patients with the following DSM-IV-TR conditions were included in the study: Depressive disorder with or without psychotic features, anxiety disorders, mixed anxiety-depressive disorder, adjustment disorder (with depressive mood, or anxious mood or mixed anxious and depressed mood). Patients who satisfied the aforementioned inclusion criteria but who had medical comorbidities or a diagnosis of personality disorder were included in the study. Those with any of the following conditions: primary psychotic disorder with secondary depression, bipolar disorder, schizoaffective disorder, other conditions with secondary depression/anxiety, substance induced conditions, organic brain conditions, and eating disorders were excluded.

The following data were collected, viz. socio-demographic characteristics, clinical diagnosis, antidepressants prescribed, and reasons for medication choices. The data collection forms were anonymized without identifiers. Any ambiguity was resolved by consensus among the investigators at meetings chaired by the second author, who is also a senior clinician in the department.

All department psychiatrists were notified of the study and written approval obtained from the prescribing doctors for investigators to study the case records of their patients. None of the treating psychiatrists was involved in data collection to avoid the possibility of bias, or conflict of interest. The study was approved by the 
hospital’s Centralised Institutional Review Board (CIRB).

\section{Statistical Analysis}

Data was analyzed using the Statistical Package for Social Sciences (SPSS) version 18 (SPSS Inc, Chicago). Descriptive statistics were performed to tabulate the socio-demographic characteristics of the sample. Frequency data was analyzed using the Fisher exact probability test, while continuous variables were analyzed using Student's unpaired t-test. A p-value of less than 0.05 was considered significant.

\section{Results}

A total of 206 patients were randomly sampled from the pool of patients. The socio-demographic characteristics are presented in Table 1.

There were 131 females (63.6\%). The majority ethnic group was Chinese (86.9\%), with age range 20-88 years, and mean age $50.6 \pm 15.2$ years for the whole sample. Majority of the patients $(70.9 \%)$ were married. Most had some form of education, with only 5.3\% having no formal education. Almost half (46.1\%) had tertiary education.

The clinical characteristics of the sample are presented in Table 2. The predominant diagnosis was depressive disorder in $50 \%$ of the sample, followed by anxiety disorder in about a quarter (27.2\%). The rest of the patients were diagnosed with mixed anxiety-depressive disorder (16\%) and adjustment disorder (5.8\%).

The duration of illness for most of the patients was between 1 to 5 years (52.9\%), while $11.7 \%$ were ill for more than 10 years and $6.8 \%$ for less than one year.

Previous medical or surgical history was reported by $68.4 \%$ of patients. The 3 most common medical comorbidities were cardiovascular, gastrointestinal and metabolic/endocrine conditions, respectively.

\subsection{Prescription Pattern of Antidepressants}

As shown in Table 3, almost all patients (97.1\%) received antidepressant medication with SSRIs, the most commonly prescribed (75.5\%), followed by NaSSA (13.5\%) and TCAs (8.5\%). Patients prescribed SSRIs upon initiation of treatment tended to be younger $(\mathrm{p}=0.0005)$ and to have at least secondary level education $(\mathrm{p}=$ 0.00017). (Please refer to Table 4).

\subsection{Switching}

Switching to another antidepressant was carried out for more than half $(52.1 \%)$ of the patients. The main reason for switching was lack of efficacy (36.7\%), side effects (30.3\%) and patients' preference (22.9\%). The most common side effects reported were headache, gastrointestinal upset (nausea and abdominal discomfort) and dizziness. Patients who suffered from cardiovascular disorders were significantly less likely to experience switching ( $\mathrm{p}=0.006$, OR $=3.3,95 \%$ CI 1.4 to 7.8$)$.

\subsection{Combination Therapy}

Combination therapy was prescribed for $17 \%$ of patients. Types of combinations are shown in Table 5 . The SSRI-NaSSA combination was the most frequently preferred in about $37 \%$ patients, followed by the SSRI-TCA combination in $20 \%$. The most cited reason for use of combination therapy was lack of efficacy in nearly half (49\%) of patients, and to improve sleep in 17\%. Combination therapy was prescribed more for patients with depression than for anxiety disorders $(\mathrm{p}=0.024)$

In contrast to other medical diagnoses, those with neurological conditions were more likely to have combination therapy ( $\mathrm{p}=0.029$, OR $=4.0,95 \%$ CI 1.2 to 13.7 ).

\subsection{Augmentation Therapy}

Augmentation therapy was prescribed for $23.8 \%(n=49)$ of the patients. Atypical antipsychotics were the most preferred augmenting agent, followed by mood stabilizers and typical antipsychotic medication. The most popular choice of atypical antipsychotic in our study was risperidone, followed by quetiapine, with olanzapine, a distant third. 
Table 1. Socio-demographic characteristics of sample.

\begin{tabular}{|ccc|}
\hline Characteristic (n = 206) & Number & \% \\
\hline Gender & 75 & $36.4 \%$ \\
\hline Male & 131 & $63.6 \%$ \\
\hline Female & & \\
\hline Race & 179 & $86.9 \%$ \\
\hline Chinese & 12 & $5.8 \%$ \\
Malay & 9 & $4.4 \%$ \\
Indian & 6 & $2.9 \%$ \\
\hline Other & & $70.9 \%$ \\
\hline Marital status & 146 & $19.9 \%$ \\
\hline Married & 41 & $5.5 \%$ \\
Single & 12 & $3.4 \%$ \\
\hline Divorced & 7 & $35.4 \%$ \\
\hline Widowed & & $5.3 \%$ \\
\hline Educational level & 11 & $16.5 \%$ \\
\hline No formal education & 34 & $32.1 \%$ \\
Primary & 66 & $46.1 \%$ \\
\hline Secondary & 95 & $60.2 \%$ \\
Tertiary & 93 & $4.4 \%$ \\
\hline Employment status & 124 & \\
\hline Full time & 93 & \\
\hline Part time & & \\
\hline Unemployed & & \\
\hline
\end{tabular}

Table 2. Clinical characteristics of sample.

\begin{tabular}{|c|c|c|}
\hline Characteristic $(n=206)$ & Number & $\%$ \\
\hline \multicolumn{3}{|l|}{ Diagnosis } \\
\hline Depressive disorder without psychotic features & 97 & $47.1 \%$ \\
\hline Depressive disorder with psychotic features & 6 & $2.9 \%$ \\
\hline Anxiety disorder & 56 & $27.2 \%$ \\
\hline Mixed anxiety-depressive disorder & 33 & $16.0 \%$ \\
\hline Adjustment disorder & 12 & $5.8 \%$ \\
\hline Others & 2 & $1.0 \%$ \\
\hline \multicolumn{3}{|l|}{ Duration of illness (years) } \\
\hline$<1$ & 14 & $6.8 \%$ \\
\hline $1-5$ & 109 & $52.9 \%$ \\
\hline $6-10$ & 59 & $28.6 \%$ \\
\hline$>10$ & 24 & $11.7 \%$ \\
\hline \multicolumn{3}{|l|}{ History of suicide attempts } \\
\hline Yes & 15 & $7.3 \%$ \\
\hline No & 191 & $92.7 \%$ \\
\hline \multicolumn{3}{|l|}{ Past medical history } \\
\hline Yes & 141 & $68.4 \%$ \\
\hline No & 65 & $31.6 \%$ \\
\hline
\end{tabular}


Table 3. Types of antidepressants prescribed on initiation of treatment.

\begin{tabular}{cc}
\hline Prescribed Antidepressants & No. (\%) \\
\hline SSRI & $151(75.5)$ \\
NaSSA & $27(13.5)$ \\
TCA & $17(8.5)$ \\
SNRI & $2(1.0)$ \\
RIMA & $1(0.5)$ \\
Others & $7(3.5)$ \\
\hline
\end{tabular}

*Some patients were on more than one antidepressant. TCA = tricyclic antidepressant; RIMA = reversible inhibitor of monoamine oxidase; SSRI = specific serotonin reuptake inhibitor; SNRI = serotonin noradrenaline reuptake inhibitor; NaSSA = noradrenaline specific serotonin antidepressant.

Table 4. Correlation of prescribing patterns of antidepressants to patient characteristics.

\begin{tabular}{cccc}
\hline Characteristic & SSRI $(\mathbf{n}=\mathbf{1 5 1})$ & TCA (n= 17) & Significance \\
\hline Age (mean) & 48.9 & 61.9 & $\mathrm{p}=0.0005$ \\
Gender & & & NS \\
Male & $53(35.1 \%)$ & $6(35.3 \%)$ & \\
Female & $98(64.9 \%)$ & $11(64.7 \%)$ & $\mathrm{p}=0.00017$ \\
Educational level & & & \\
Up to secondary level & $29(19.2 \%)$ & $11(64.7 \%)$ & $\mathrm{NS}$ \\
Secondary and above & $122(80.8 \%)$ & $6(35.3 \%)$ & $\mathrm{N}=16$ \\
Diagnosis & $\mathrm{N}=141$ & $7(43.7 \%)$ & \\
Depressive illness & $76(65.5 \%)$ & $7(43.7 \%)$ & $2(12.6 \%)$ \\
Anxiety disorder & $40(34.5 \%)$ & $25(17.7 \%)$ & \\
Mixed anxiety-depression &
\end{tabular}

SSRI = specific serotonin reuptake inhibitor; TCA = tricyclic antidepressant; ${ }^{*}$ patients with other diagnoses were not included in the analysis.

\section{Table 5. Types of Combination therapy.}

\begin{tabular}{cc}
\hline Combinations & $\mathbf{n}=\mathbf{3 5}(\mathbf{1 0 0} \%)$ \\
\hline SSRI + NaSSA & $13(37.1 \%)$ \\
SSRI + TCA & $7(20.0 \%)$ \\
SSRI + trazodone & $4(11.5 \%)$ \\
SSRI + SNRI & $1(2.9 \%)$ \\
SSRI + SSRI & $2(5.7 \%)$ \\
SSRI + bupropion & $2(5.7 \%)$ \\
TCA + SNRI & $2(5.7 \%)$ \\
TCA + NaSSA & $2(5.7 \%)$ \\
Others & $2(5.7 \%)$ \\
\hline
\end{tabular}

TCA = tricyclic antidepressant; RIMA = reversible inhibitor of monoamine oxidase; SSRI = specific serotonin reuptake inhibitor; SNRI = serotonin noradrenaline reuptake inhibitor; NaSSA = noradrenaline specific serotonin antidepressant.

The main reasons for augmentation therapy were the presence of comorbid conditions (36.7\%) and lack of efficacy (20.4\%) of single agent therapy. Augmentation was prescribed more frequently for patients suffering from depression $(\mathrm{p}=0.033$ ) compared to other conditions (please refer to Table 6).

There were no associations between age and sex with switching, augmentation or combination therapy (in all cases $\mathrm{p}>0.05)$.

\section{Discussion}

Compared to the general population, there was an over representation of Chinese patients in the study, which could be a reflection of the demographic characteristics of patients referred to the hospital, or living in the Tanjong Pagar constituency where the hospital is sited. According to the Singapore Elections Department, the num- 
Table 6. Relationship between therapy and clinical characteristics.

\begin{tabular}{|cccc}
\hline Characteristic & Combination & Monotherapy & Significance \\
\hline Diagnosis & $\%$ & $\%$ & $\mathrm{p}=0.024$ \\
\hline Depressive disorder & 84.6 & 60.9 & NS \\
\hline Anxiety disorder & 15.4 & 39.1 & Significance \\
\hline Duration of illness & & 60.2 & $\mathrm{p}=0.033$ \\
\hline$<5$ years & 57.1 & 39.8 & \\
$>5$ years & 42.9 & No augmentation & NS \\
\hline & Augmentation & 60 & 40 \\
\hline Diagnosis & $\%$ & & \\
\hline Anxiety disorder & 79.5 & 59.9 & \\
\hline Duration of illness & 20.5 & 40.1 & \\
\hline & & & \\
\hline
\end{tabular}

ber of eligible voters within the constituency in 2014 was 137,464 persons [17]. Thus a generous estimate of the size of the hospital's catchment area, which includes non-voters, temporary residents, and non-citizens would be about 180,000 persons.

A greater preponderance of females in this sample is consistent with the higher prevalence of anxiety and depression in females in Singapore [18] [19].

Almost all patients in our study (97\%) were offered treatment with an antidepressant, of which SSRIs were the most commonly prescribed. This is in keeping with the results of studies done in Asia [5] [17] [20], the United States [4] and Europe [21] which supported this finding.

SSRI usage has been previously associated with younger age, female gender and diagnosis of depression, compared to TCAs [22]. These findings were also reflected in our study, which suggested that those prescribed SSRIs tended to be better educated. There was no correlation with gender in our sample.

The use of "dual-action" antidepressants, for example NaSSAs and SNRIs, has been on the rise in recent years. Mirtazapine (NaSSA) and venlafaxine (SNRI) were the $2^{\text {nd }}$ and $4^{\text {th }}$ most commonly used antidepressants in this study. Some researchers have suggested that the treatment of depression with newer antidepressants that enhance both norepinephrine and serotonin neurotransmission may result in higher response and remission rates than SSRIs [23].

Treatment is not always effective, and some found that only one third of patients achieve full remission after their first antidepressant treatment in a naturalistic setting [24]. In our case, efficacy was assessed by the treating psychiatrist based on clinical examination of patients, as formal rating scales were not utilized in our clinics.

Our study revealed that more than half required switching. About a third cited side effects and another third efficacy issues. This is in keeping with our hypothesis that intolerance to side effects and a lack of efficacy contribute to switching before settling on the final choice of antidepressant. Whether our patients were more likely to experience side effects, or report side effects, compared to those from the West is open to question. It appears that a greater proportion in our study required switching compared to those from other countries. While it is possible that our patients are more prone to side effects, this observation was supported by Lin who suggested that Asians metabolize drugs in the CYP4502D6 system more slowly than patients of other ethnic groups, and hence it were more likely to develop side effects at lower doses compared to their Western counterparts [25]. In order to avoid side effects, we usually start with lower dosages, and thereafter titrate them upwards cautiously. Taking our most commonly prescribed SSRI, Fluvoxamine, as an example, we used starting dosages as low as $25 \mathrm{mg}$ for anxiety disorder. Our average dose of this medication was $77.5 \mathrm{mg}$. This is below the recommended range of 100 - $300 \mathrm{mg}$ for this drug in the European guidelines [26]. Whereas in the case of Fluoxetine, our average dose was $36 \mathrm{mg}$, within the recommended range of 20 - $40 \mathrm{mg}$ [26].

There are many options available for switching, including use of a second SSRI, novel dual-acting antidepressants, selective norepinephrine or noradrenergic/dopaminergic agents, TCAs or mianserin [27]. However, in 
our hospital, mianserin is not available, although a drug similar in structure to mianserin viz. mirtazapine appears to be used as a drug of second choice.

The proportion of patients who were switched to another class of antidepressants for this study was $52.9 \%$, which appears to be a higher rate compared to other studies. For example, researchers in France, based on a general practice database, showed that $16 \%$ of patients switched antidepressants, with $72 \%$ occurring within 3 months of treatment initiation [28]. Others reported switching for the purpose of optimizing treatment in about $40 \%$ of patients [29].

In our study, $17 \%$ of patients received combination therapy. Although our preferred combination was SSRINaSSA, with the exception of a few small studies demonstrating the efficacy of this method [30] [31], the literature is generally rather sparse in regards the use of this approach. Combinations involving other classes of antidepressants have been described [32]-[34] (although used less commonly in our hospital).

An interesting observation of our study was the combination of trazodone and SSRI. Although trazodone is an older antidepressant, it has been used more as a sedative hypnotic in recent times [35]. This could explain its relative lack of utility as a combination agent elsewhere. Some have found that the SSRI-trazodone combination could be useful in alleviating the sleep problems associated with SSRI monotherapy [36], which is in keeping with the fact that the second most common reason for combination was for improvement of sleep. The addition of buproprion or an SNRI to an SSRI were the popular options in other studies [9] [29], although less preferred in our department. This could be due to the relative infrequent use of Bupropion or of SNRIs in our hospital, a reflection of prescribing habits rather than availability.

This study shows that $23.8 \%$ of patients had augmentation therapy. This is similar to the $20 \%$ quoted in a study done in Korea [20]. In a multi-centre study in Spain, Garcia-Toro et al. found that about 19\% patients [29] were prescribed augmentation therapy, with atypical antipsychotics being the more common choice (rather similar to our case).

The lack of association between age and sex with switching, combination or augmentation therapies would suggest that strategies to alleviate side effects or lack of efficacy were implemented regardless of demographic characteristics of the patient. Patients with cardiovascular conditions were significantly less likely to be switched to another antidepressant in the event of poor response or when they experienced side effects. For instance, there was no association between cardiovascular problems and the use of augmentation ( $p=0.629)$, or combination therapy $(\mathrm{p}=0.064)$. This would suggest that our psychiatrists tended to be more cautious with cardiac patients, preferring to wait for the initial antidepressant to take effect rather than try other medications or strategies to overcome efficacy problems.

In contrast, those with neurological comorbidities were more likely to receive combination therapy, as our clinicians probably felt that such strategies were not likely to worsen their patients' neurological status.

A retrospective study with a small sample size has its limitations, the most common problem being missing data or illegible entries in case records. As a naturalistic observational study with broad inclusion criteria, it has not been possible to control for clinical and socio-economical characteristics of the sample population, thus limiting inferences about cause-and-effect relationships. As we only analyzed outpatients receiving care from psychiatrists, our findings could neither be generalized to mild depressive patients, mainly managed by family physicians, nor the severely ill in the inpatient population.

\section{Conclusion}

Notwithstanding some limitations, this is the first study to examine antidepressant prescription patterns in a Singapore hospital. Our findings confirmed the hypothesis that antidepressant therapy was not easy for patients to tolerate. Side effects may seriously reduce treatment adherence and efficacy, hence necessitating strategies of switching, augmentation and combination prescriptions. Conversely, these options could also be selected for efficacy problems in the absence of side effects. This raises the need for further research to examine the extent of treatment non-adherence, and to correlate this with attitudes towards intake of psychiatric medications and their side effects.

\section{Acknowledgements}

The authors would like to thank Joyce Lim, a research assistant, for her help in data collection, and Dr Ng Kah Wee and Dr Cecilia Kwok for assistance rendered during the preparation of this manuscript. 


\section{References}

[1] Abbing-Karahagopian, V., Huerta, C., Souverein, P.C., de Abajo, F., Leufkens, H.G.M., Slattery, J., et al. (2014) Antidepressant Prescribing in Five European Countries: Application of Common Definitions to Assess the Prevalence, Clinical Observations, and Methodological Implications. European Journal of Clinical Pharmacology, 70, 49-57. http://dx.doi.org/10.1007/s00228-014-1676-z

[2] Exeter, D., Robinson, E. and Wheeler, A. (2009) Antidepressant Dispensing Trends in New Zealand between 2004 and 2007. Australia and New Zealand Journal of Psychiatry, 43, 1131-1140. http://dx.doi.org/10.3109/00048670903279879

[3] National Institute for Clinical Excellence (2004) Management of Depression in Primary and Secondary Care. Clinical Guideline 23. National Institute for Clinical Excellence, London. http://www.nice.org.uk/pdf/CG023quickrefguide.pdf

[4] Ivanova, J.I., Bienfait-Beuzon, C., Birnbaum, H.G., Connolly, C., Emani, S. and Sheehy, M. (2011) Physicians’ Decisions to Prescribe Antidepressant Therapy in Older Patients with Depression in a US Managed Care Plan. Drugs and Aging, 28, 51-62. http://dx.doi.org/10.2165/11539900-000000000-00000

[5] Zhang, Y., Becker, T., Kösters, M. (2013) Preliminary Study of Patterns of Medication Use for Depression Treatment in China. Asia-Pacific Psychiatry, 5, 231-236. http://dx.doi.org/10.1111/appy.12022

[6] Zimmerman, M., Posternak, M., Friedman, M., Attiullah, N., Baymiller, S., Boland, R., et al. (2004) Which Factors Influence Psychiatrists' Selection of Antidepressants? The American Journal of Psychiatry, 161, 1285-1289. http://dx.doi.org/10.1176/appi.ajp.161.7.1285

[7] Bauer, M., Adli, M., Ricken, R., Severus, E. and Pilhatsch, M. (2014) Role of Lithium Augmentation in the Management of Major Depressive Disorder. CNS Drugs, 28, 331-342. http://dx.doi.org/10.1007/s40263-014-0152-8

[8] Joffe, R.T. and Schuller, D.R. (1993) An Open Study of Buspirone Augmentation of Serotonin Reuptake Inhibitors in Refractory Depression. The Journal of Clinical Psychiatry, 54, 269-271.

[9] Spier, S.A. (1998) Use of Bupropion with SRIs and Venlafaxine. Depression and Anxiety, 7, 73-75. http://dx.doi.org/10.1002/(SICI)1520-6394(1998)7:2<73::AID-DA4>3.0.CO;2-6

[10] Shelton, R.C., Tollefson, G.D., Tohen, M., Stahl, S., Gannon, K.S., Jacobs, T.G., et al. (2001) A Novel Augmentation Strategy for Treating Resistant Major Depression. The American Journal of Psychiatry, 158, 131-134. http://dx.doi.org/10.1176/appi.ajp.158.1.131

[11] Carpenter, L.L., Yasmin, S. and Price, L.H. (2002) A Double-Blind Placebo-Controlled Study of Antidepressant Augmentation with Mirtazapine. Biological Psychiatry, 51, 183-188. http://dx.doi.org/10.1016/S0006-3223(01)01262-8

[12] Shelton, R.C., Osuntokun, O., Heinloth, A.N. and Corya, S.A. (2010) Therapeutic Options for Treatment-Resistant Depression. CNS Drugs, 24, 131-161. http://dx.doi.org/10.2165/11530280-000000000-00000

[13] Ammar, G., Naja, W.J. and Pelissolo, A. (2014) Treatment-Resistant Anxiety Disorders: A Literature Review of Drug Therapy Strategies. Encéphale, 14, pii: S0013-7006(14)00040-2.

[14] Spijker, J. and Nolen, W.A. (2010) An Algorithm for the Pharmacological Treatment of Depression. Acta Psychiatrica Scandinavica, 121, 180-189. http://dx.doi.org/10.1111/j.1600-0447.2009.01492.x

[15] Elections Department, Singapore (2014) http://www.eld.gov.sg/elections_type_electoral.html

[16] Uchida, N., Chong, M.Y., Tan, C.H., Nagai, H., Tanaka, M., Lee, M.S., et al. (2007) International Study on Antidepressant Prescription Pattern at 20 Teaching Hospitals and Major Psychiatric Institutions in East Asia: Analysis of 1898 Cases from China, Japan, Korea, Singapore and Taiwan. Psychiatry and Clinical Neurosciences, 61, 522-528. http://dx.doi.org/10.1111/j.1440-1819.2007.01702.x

[17] Sim, K., Lee, N.B., Chua, H.C., Mahendran, R., Fujii, S., Yang, S.Y., et al. (2007) Newer Antidepressant Drug Use in East Asian Psychiatric Treatment Settings: REAP (Research on East Asia Psychotropic Prescriptions) Study. British Journal of Clinical Pharmacology, 63, 431-437. http://dx.doi.org/10.1111/j.1365-2125.2006.02780.x

[18] Lim, L., Ng, T.P., Chua, H.C., Chiam, P.C., Won, V., Lee, T., et al. (2005) Generalised Anxiety Disorder in Singapore: Prevalence, Co-Morbidity and Risk Factors in a Multi-Ethnic Population. Social Psychiatry and Psychiatric Epidemiology, 40, 972-979. http://dx.doi.org/10.1007/s00127-005-0978-y

[19] Chua, H.C., Lim, L., Ng, T.P., Lee, T., Mahendran, R., Fones, C. and Kua, E.H. (2004) The Prevalence of Psychiatric Disorders in Singapore Adults. Annals Academy of Medicine Singapore, 33, S102.

[20] Bae, K.Y., Kim, S.W., Kim, J.M., Shin, I.S., Yoon, J.S., Jung, S.W., et al. (2001) Antidepressant Prescribing Patterns in Korea: Results from the Clinical Research Center for Depression Study. Psychiatry Investigation, 8, 234-244.

[21] Bauer, M., Monz, B.U., Montejo, A.L., Quail, D., Dantchev, N., Demyttenaere, K., et al. (2008) Prescribing Patterns of Antidepressants in Europe: Results from the Factors Influencing Depression Endpoints Research (FINDER) Study. European Psychiatry, 23, 66-73. http://dx.doi.org/10.1016/j.eurpsy.2007.11.001 
[22] Sclar, D.A., Robinson, L.M., Skaer, T.L. and Galin, R.S. (1998) What Factors Influence the Prescribing of Antidepressant Pharmacotherapy? An Assessment of Office-Based Encounters. International Journal of Psychiatry in Medicine, 28, 407-419. http://dx.doi.org/10.2190/6VR0-XRCG-G1H3-N9Q0

[23] Papakostas, G.I., Thase, M.E., Fava, M., Nelson, J.C. and Shelton, R.C. (2007) Are Antidepressant Drugs That Combine Serotonergic and Noradrenergic Mechanisms of Action More Effective than the Selective Serotonin Reuptake Inhibitors in Treating Major Depressive Disorder? A Meta-Analysis of Studies of Newer Agents. Biological Psychiatry, 62, 1217-1227. http://dx.doi.org/10.1016/j.biopsych.2007.03.027

[24] Rush, A.J., Trivedi, M.H., Wisniewski, S.R., Nierenberg, A.A., Stewart, J.W., Warden, D., et al. (2006) Acute and Longer-Term Outcomes in Depressed Outpatients Requiring One or Several Treatment Steps: A STAR*D Report. American Journal of Psychiatry, 163, 1905-1917. http://dx.doi.org/10.1176/ajp.2006.163.11.1905

[25] Lin, K.M. (2001) Biological Differences in Depression and Anxiety across Races and Ethnic Groups. Journal of Clinical Psychiatry, 62, 13-19.

[26] Bandelow, B., Zohar, J., Hollander, E., Kasper, S., Möller, H.J., et al. (2008) World Federation of Societies of Biological Psychiatry (WFSBP) Guidelines for the Pharmacological Treatment of Anxiety, Obsessive-Compulsive and Post- Traumatic Stress Disorders-First Revision. World Journal of Biological Psychiatry, 9, 248-312. http://dx.doi.org/10.1080/15622970802465807

[27] Connolly, K.R. and Thase, M.E. (2001) If at First You Don’t Succeed: A Review of the Evidence for Antidepressant Augmentation, Combination and Switching Strategies. Drugs, 71, 43-64. http://dx.doi.org/10.2165/11587620-000000000-00000

[28] Saragoussi, D., Chollet, J., Bineau, S., Chalem, Y. and Milea, D. (2012) Antidepressant Switching Patterns in the Treatment of Major Depressive Disorder: A General Practice Research Database Study. International Journal of Clinical Practice, 66, 1079-1087. http://dx.doi.org/10.1111/j.1742-1241.2012.03015.x

[29] Garcia-Toro, M., Medina, E., Galan, J.L., Gonzalez, M.A. and Maurino, J. (2012) Treatment Patterns in Major Depressive Disorder after an Inadequate Response to First Line Antidepressants. BMC Psychiatry, 12, 143. http://dx.doi.org/10.1186/1471-244X-12-143

[30] Debonnel, G., Gobbi, G., Turcotte, J., Boucher, N., Hébert, C., De Montigny, C. and Blier, P. (2000) Effects of Mirtazapine, Paroxetine and Their Combination: A Double-Blind Study in Major Depression. European Neuropsychopharmacology, 10, 252. http://dx.doi.org/10.1016/S0924-977X(00)80213-8

[31] Anttila, S.A. and Leinonen, E.V. (2001) A Review of the Pharmacological and Clinical Profile of Mirtazapine. CNS Drug Reviews, 7, 249-264. http://dx.doi.org/10.1111/j.1527-3458.2001.tb00198.x

[32] Horgan, D., Dodd, S. and Berk, M. (2007) A Survey of Combination Antidepressant Use in Australia. Australasian Psychiatry, 15, 26-29. http://dx.doi.org/10.1080/10398560601109855

[33] Shelton, R.C. (2003) The Use of Antidepressants in Novel Combination Therapies. Journal of Clinical Psychiatry, 64, 14-18.

[34] Lam, R.W., Wan, D.C., Cohen, N.L. and Kennedy, S.H. (2002) Combining Antidepressants for Treatment Resistant Depression: A Review. Journal of Clinical Psychiatry, 63, 685-693. http://dx.doi.org/10.4088/JCP.v63n0805

[35] Schatzberg, A.F. (1987) Trazodone: A 5-Year Review of Antidepressant Efficacy. Psychopathology, 20, 48-56. http://dx.doi.org/10.1159/000284523

[36] Fagiolini, A., Comandini, A., Catena Dell’Osso, M. and Kasper, S. (2012) Rediscovering Trazodone for the Treatment of Major Depressive Disorder. CNS Drugs, 26, 1033-1049. http://dx.doi.org/10.1007/s40263-012-0010-5 